D.O.I.: $10.3895 / \mathrm{S} 1808-04482007000200005$

\title{
A GESTÃO DE ESTRATÉGIAS COM O USO DO BALANCED SCORECARD GARANTE O ALCANCE DOS OBJETIVOS ESTRATÉGICOS?
}

\section{DOES STRATEGYC MANAGEMENT THROUGH THE BALANCED SCORECARD ASSURE THE ACHIEVEMENT OF STRATEGYC OBJECTIVES?}

\author{
José Tarcísio Greve ${ }^{1}$; Dr. José Antonio Arantes Salles ${ }^{2}$ \\ ${ }^{1}$ UNIMEP-Santa Bárbara d'Oeste - Brasil greve.idt@terra.com.br \\ ${ }^{2}$ Profs - UNIMEP-Santa Bárbara d'Oeste - Brasil jasalles@unimep.br
}

\begin{abstract}
Resumo
O objetivo deste artigo é discutir os principais resultados de um estudo de caso em relação à implementação e gestão de estratégias com o uso do Balanced Scorecard-BSC. Baseia-se na busca por vantagens competitivas e no gerenciamento das operações, onde o ambiente competitivo força as empresas a reverem suas estratégias e competências. A gestão estratégica e a análise do desempenho deve se basear em sistemas de indicadores que mostrem coerência entre os indicadores, os fatores críticos de sucesso, as estratégias competitivas e os objetivos estratégicos. Estratégias bem formuladas não são suficientes se não houver implementação e controle, ou seja, uma gestão voltada para o alcance dos objetivos estratégicos. O BSC proporciona ampla compreensão das estratégias, explicando onde cada funcionário se encaixa no mapa estratégico e como pode contribuir para o alcance dos objetivos. Embora favoreça o alcance dos objetivos estratégicos das várias perspectivas, não garante, em casos particulares, o alcance dos principais objetivos da perspectiva financeira.
\end{abstract}

Palavras-chave: gestão de estratégias; sistemas de medição de desempenho; balanced scorecard; vantagem competitiva.

\section{Introdução}

A partir de meados da década de 80 as mudanças no ambiente competitivo foram bastante significativas e a competição global passou a exercer pressão cada vez maior sobre as empresas e organizações. No caso das empresas brasileiras isto ficou mais evidente somente a partir do inicio da década de 90, com a abertura da economia brasileira às importações.

Hoje, graças à competição global e a grande oferta de produtos e serviços, pessoas e empresas estão muito mais exigentes e mais conscientes sobre preços, prazos, qualidade e serviços pós-venda. Elas buscam um pacote de conveniências que atenda as suas necessidades e que agregue valor a si mesmas ou a seus negócios. Neste ambiente de rápidas mudanças, nada é constante ou 
previsível; nem o crescimento do mercado, a demanda e necessidades dos clientes, o ciclo de vida dos produtos, o grau da mudança tecnológica ou até mesmo a natureza da competição. Isto força as empresas a reverem suas estratégias e competências para responder, e até mesmo se antecipar, de forma positiva às mudanças.

Um planejamento estratégico adequado deve considerar todas as possibilidades para maximizar o uso dos recursos materiais e humanos, reduzir custos tangíveis e intangíveis, inovar e se antecipar às necessidades atuais e futuras dos clientes, definindo estratégias e sistemas de gestão para assegurar a competitividade, a rentabilidade, agregar valor ao negócio e satisfazer, não só o acionistas mas todos os demais "stakeholders". Isto inclui não apenas o redirecionamento estratégico e a reconfiguração do desempenho das operações mas, principalmente, o uso de sistemas adequados de medição de desempenho e uma efetiva gestão das estratégias.

Kershaw (2004) argumenta que em uma economia de baixo crescimento, competição global, e aumento das expectativas dos clientes, unir as ações gerenciais do dia a dia com a estratégia torna-se mais necessário que nunca. As empresas que conseguirem, rapidamente, ajustar seus sistemas de medição de desempenho para refletir o ajuste da estratégia poderão aumentar suas chances de sobreviver e crescer.

Enquanto Hawawini et al. (2003) defendem que são os fatores específicos (competências) de cada empresa que fazem a diferença no seu desempenho financeiro, e não as características do setor no qual ela se enquadra. Hitt et al. (2005) argumentam que os retornos superiores são determinados pelas características externas e não somente pelos recursos e capacidades exclusivos de uma empresa, e acrescentam que tanto o ambiente externo quanto as capacidades da empresa são importantes na determinação da sua rentabilidade.

Com o objetivo de investigar se a introdução de um sistema de medição de desempenho, baseado no BSC, pode contribuir para a implementação e revisão das estratégias, e para o alcance dos objetivos definidos no planejamento estratégico, foi realizado um estudo de caso em uma empresa multinacional do setor de autopeças buscando responder a seguinte pergunta: Um sistema de medição de desempenho estruturado e formalizado é suficiente para o alinhamento entre a Missão, Visão de futuro, estratégias e os objetivos estratégicos e, ainda, colabora para o alcance dos objetivos estratégicos relacionados com os resultados financeiros?

O presente artigo foi desenvolvido a partir de um estudo de caso e possui três objetivos. Primeiro explora os principais conceitos de estratégia e competitividade e, em seguida trata da gestão de estratégias por meio da medição do desempenho. Por último apresenta o estudo de caso e suas conclusões.

Conforme Yin (2001), o estudo de caso é uma investigação empírica baseada em evidências, observações diretas e uma série sistemática de entrevistas para esclarecer um conjunto de decisões, 
os motivos pelos quais foram tomadas, como foram implementadas e quais os resultados alcançados. Neste caso, trata-se de uma pesquisa participante que se desenvolve entre o pesquisador, que trabalha na empresa, e os demais membros da situação pesquisada.

\section{Estratégia e competitividade}

As empresas sabem há tempos que para serem competitivas, precisam elaborar uma boa estratégia e alinhar corretamente a Missão e a Visão de futuro com a estrutura, sistemas, comportamento da liderança, políticas de recursos humanos, cultura, valores, processos gerenciais,etc.

Em relação à estratégia, Mintzberg (2001) argumenta que não existe uma melhor estratégia e nenhuma receita funciona da mesma forma para todas as organizações. Mesmo quando uma receita parece ser eficiente em um determinado contexto (situação ou ambiente competitivo), ela requer uma compreensão completa do que é exatamente o contexto em questão e como este funciona. Não se pode decidir, de forma confiável, o que deve ser feito em um sistema tão complicado quanto uma organização contemporânea, sem uma profunda compreensão de como essa organização realmente funciona.

Aparentemente poucas são as empresas que tem cultura, estrutura e liderança do tipo necessário para transformar seus recursos internos em vantagem competitiva relevante. Mintzberg (2001) complementa que a estratégia lida com a continuidade, não com a mudança. A estratégia preocupa-se em impor padrões estruturais de comportamento em uma organização. Hoje, porém, administrar a estratégia é administrar a mudança, reconhecendo quando uma alteração de natureza estratégica é possível, desejável ou necessária e, em seguida, agir.

Quanto ao gerenciamento e implantação das estratégias, Kaplan e Norton (2004) citam um estudo realizado pela Bain \& Company, que analisou o desempenho de grandes empresas com faturamento acima de US\$500 milhões, em sete paises desenvolvidos. O estudo demonstrou que a maioria das empresas não é bem sucedida na implantação da estratégia, e por isso, menos de 10\% dessas empresas atingiu suas metas. Kaplan e Norton (2001) citam que uma pesquisa entre 275 gerentes de empresas concluiu que a capacidade de executar a estratégia é mais importante do que a qualidade da estratégia em si.

Um aspecto importante para a definição das estratégias de uma unidade de negócios é a abordagem desenvolvida por Hill (1989) sobre os critérios qualificadores e critérios ganhadores de pedidos. Este conceito é muito importante na definição das estratégias de manufatura uma vez que esses critérios são equivalentes às prioridades competitivas e fatores críticos de sucesso da organização. 
Conforme Hill (1989) e Slack et al. (2001), critérios qualificadores são aqueles aspectos da competitividade nos quais o desempenho da manufatura deve estar acima de um nível determinado considerado pelo cliente. Abaixo deste nível qualificador de desempenho, a empresa provavelmente nem mesmo será considerada como fornecedora potencial. Podem não ser os principais determinantes do sucesso competitivo, mas são importantes para manter a empresa em paridade com os concorrentes. Exemplos de critérios qualificadores podem ser a certificação dos sistemas da qualidade conforme as normas ISO 9000, ISO 14000 e/ou outras certificações específicas.

Os critérios ganhadores de pedido são os que contribuem direta e significativamente para a realização de um negócio, ou seja, para se fechar um pedido. São considerados pelos consumidores como razões chaves para comprar o produto ou serviço. Aumentar o desempenho em um critério ganhador de pedidos melhora a probabilidade de ganhar mais pedidos. Exemplo de critério ganhador de pedidos pode ser, entre outros, o custo do produto ou mesmo a flexibilidade ou prazo de entregas.

Aos critérios qualificadores e ganhadores de pedido de Hill, Slack et al. (2001), acrescentam os critérios menos importantes, os quais não influenciam os clientes de forma significativa e direta, mas podem influenciar a produtividade da produção e também os custos. Eles fazem um alerta em relação ao gerenciamento da qualidade total (TQM) e ressaltam que o custo associado ao esforço de melhoria da qualidade é pequeno se comparado ao custo de não ter qualidade, mas existe um ponto além do qual os custos da melhoria tornam-se maiores que os benefícios gerados. Isto poderá acrescentar custos por atividades que não agregam valor para o cliente.

Para Neely et al. (2002), organizações são entidades complexas que consistem de um número de pessoas trabalhando com o propósito comum de fornecer valor para os clientes. Em teoria a estratégia explica o que a organização irá fazer, o que não ira fazer e porque estas escolhas foram feitas. Na prática as estratégias, freqüentemente são vagas, não firmemente relacionadas e difíceis de implementar. Eles citam que uma das razões porque recentemente a medição de desempenho se tornou tão popular, é porque ela provê meios para superar estes problemas.

\section{Gestão da estratégia por meio da medição do desempenho}

Tangen (2004) comenta que o principal objetivo de um sistema de medição de desempenho (SMD) é encorajar um gerenciamento pró - ativo e focado nos resultados de curto e de longo prazo nos diferentes tipos de desempenho (custo, qualidade, pontualidade de entregas, flexibilidade e confiabilidade), nas diferentes perspectivas (clientes, acionistas, competidores, processos internos e do aprendizado e inovação) e em todos os níveis organizacionais. 
Kennerly e Neely $(2002,2003)$ e Bourne et al. (2005) comentam que são poucas as evidencias de que as organizações estão gerenciando seus SMD de maneira a refletir o contexto organizacional. Eles também alertam que as organizações estão introduzindo novos indicadores para refletir as novas prioridades estratégicas e, sem descartar os indicadores das prioridades anteriores, estão se afogando em um monte de dados fracamente correlacionados e não consistentes. Para Fletcher (2004), uma vez que o comportamento das pessoas, e da organização como um todo, é determinado pelo que é medido e recompensado, os indicadores de desempenho financeiros tradicionais não mais refletem a realidade do ambiente atual. Os novos SMD's devem contemplar indicadores financeiros e não-financeiros.

A gestão estratégica e a análise do desempenho deve se basear em sistemas de indicadores que mostrem coerência entre os indicadores, os fatores críticos de sucesso, as estratégias competitivas e os objetivos estratégicos. Bourne et al. (2005) comentam que existem poucos estudos sobre como o uso da medição de desempenho realmente impacta o desempenho final das empresas.

Voelpel et al. (2005) vão um pouco além das estratégias competitivas e objetivos estratégicos e argumentam que as empresas devem implementar SMD que dêem uma ampla visão de todo o sistema sócio cultural do negócio. Robson (2005) ainda complementa que o SMD deve considerar a cultura e as conseqüências psicológicas dos envolvidos, uma vez que a maneira como o SMD é desenvolvido pode torná-lo um facilitador ou servir de barreira ao alcance dos objetivos estratégicos.

Para que as estratégias sejam implementadas e alcancem o seu potencial de sucesso, é necessário comprometimento para sua execução. Existe, porém, uma importante condição que afeta profundamente a qualidade das decisões; aqueles que tomam as decisões precisam estar plenamente identificados com a organização e seus objetivos, motivados e comprometidos na busca de soluções, ou alternativas, que melhor assistam a organização na consecução de seus objetivos. Waal (2004) ainda comenta que na prática, é necessário que os membros da organização demonstrem um comportamento fortemente direcionado para o desempenho. FPNQ, 2002, p. 7

\footnotetext{
A questão não é se o sistema de medição do desempenho de uma organização é importante ou não, mas se a medição sistemática, seguindo uma estrutura planejada ${ }_{2}$ faz diferença na capacidade de uma organização apresentar resultados excelentes e sustentáveis. A medição sistemática e estruturada permite às organizações monitorar seu desempenho e, desta forma, realizar mudanças rapidamente com base em informações pertinentes e confiáveis, conforme ocorrem as mudanças no mercado. O estudo das organizações que tem se mantido na liderança em seus setores de atuação por longos períodos mostra que a habilidade de medir sistematicamente seu próprio desempenho, e de usar a medição inteligentemente para buscar patamares superiores, é uma característica sempre presente.
}

\subsection{Sistemas de medição de desempenho - SMD}


Para Kaplan e Norton (2001), os indicadores de desempenho revelam-se, imprescindíveis e devem ser considerados como ferramenta de suporte aos processos de planejamento estratégico e de controle das estratégias adotadas e implementadas.

$\mathrm{Na}$ busca por maior competitividade e, considerando que a qualidade das decisões de uma organização repousa firmemente na adequação e exatidão dos fatos disponíveis àqueles que tomam decisões, Bourne et al. (2003) e Neely (1998) definem que SMD são, literalmente, o processo de quantificar as ações que levam ao desempenho. Eles definem eficácia como sendo a dimensão na qual os requisitos dos clientes são alcançados e satisfeitos, ao passo que eficiência é a medição de como, economicamente, os recursos da organização são utilizados para prover tal nível de satisfação. Um SMD pode ser definido como um conjunto de indicadores usados para quantificar a eficiência e eficácia das ações e decisões tomadas.

Bourne et al. (2003) ainda complementam que um SMD é um conjunto de indicadores multidimensionais que incluem indicadores financeiros e não-financeiros e indicadores externos e internos usados para planejar e gerenciar um negócio. A medição de desempenho não deve ser usada isoladamente e, só é relevante se estiver estruturada de maneira a permitir a comparação da eficiência e eficácia das ações e avaliar o impacto sobre os "stakeholders".

O processo de decidir o que medir, conforme Neely et al. (2002), tão importante quanto o que não medir, força os gestores a definir e explicitar as prioridades estratégicas. Quando os indicadores são consistentes com as estratégias da organização, eles encorajam comportamentos que são consistentes com a estratégia, então, medições adequadas não apenas oferece meios de comunicação da estratégia, mas também encorajam sua implementação.

Para Simons (2000), o comportamento humano é diretamente ligado às tensões organizacionais que afetam a todos e, embora as pessoas sintam orgulho das suas habilidades e queira contribuir, alcançar resultados, inovar e agir de maneira competente, muitas vezes elas não apresentam estes comportamentos devido às barreiras, freqüentemente, criadas pelas próprias organizações. O projeto e definição dos SMD's não pode deixar de levar em consideração o comportamento humano e as causas e efeitos destas barreiras:

- A empresa dificulta o processo de entendimento de como as pessoas podem contribuir e fazer alguma diferença. As pessoas podem não entender qual é a estratégia e a direção do negócio, por não conhecer a Missão da empresa e como cada um se encaixa nela;

- A empresa cria tensões, medos e "tentações" nas pessoas. A pressão por desempenho pode levar funcionários a manipular as regras e procedimentos ou esconder informações com medo de serem substituídos. Por outro lado, os prêmios por desempenho (tentações) podem levar funcionários a passar dos limites e manipular dados e informações; 
- Alcançar resultados pode ser dificultado pela não disponibilidade de recursos, ou sobrecarga de trabalho que não permite focar os objetivos com a intensidade necessária $\mathrm{e}$;

- As pessoas podem falhar em inovar devido a não disponibilidade dos meios e recursos necessários ou pelo medo do risco e do desafio da situação vigente.

Kaplan e Norton (1997) e Niven (2005) acrescentam que a incoerência entre a formulação e a implementação de estratégias é causada por barreiras criadas pelos sistemas gerenciais tradicionais para comunicar as estratégias, alocar recursos, definir as metas para os departamentos, equipes e indivíduos e o sistema de "feedback". Eles identificaram quatro barreiras especificas na implementação das estratégias; visões e estratégias não executáveis; estratégias não associadas às metas de departamentos, equipes e indivíduos; estratégias não associadas à alocação de recursos a curto e longo prazos e; sistema de "feedback” tático e não estratégico.

A questão do comportamento e comprometimento organizacional talvez seja o ponto mais importante na discussão do por que a maioria das falhas estratégicas nas empresas está relacionada à sua implementação e execução. Sobre isso, Lawrie et al. (2004), enfatizam que o uso da relação de causa e efeito para dar suporte à articulação dos objetivos estratégicos é consistente com os trabalhos de vários autores sobre mudanças organizacionais e aprendizagem.

Para Chenhall (2005), as teorias do aprendizado organizacional indicam que um SMD integrado pode favorecer o aprendizado e levar ao sucesso dos resultados. O aprendizado ao nível da organização parece aumentar a intensidade do conhecimento, o qual é pré-requisito para o desenvolvimento de respostas estratégicas no ambiente. Bases teóricas da área da psicologia sugerem que as pessoas são mais motivadas quando tem metas a cumprir e são suportadas por um processo de feedback que integra as ações e os resultados. As metas direcionam o comportamento e o feedback melhora o desempenho.

Chenhall (2005) ainda reforça que um sistema de comunicação eficiente faz uma ligação entre os que tem as informações e os que precisam dela, e isto ajuda a identificar o conhecimento dentro da organização. A distribuição das informações assegura que mais indivíduos estarão conscientes da natureza da estratégia e poderão melhor contribuir para o alcance dos objetivos e fornecer "feedback" na adequação das alternativas potenciais.

Para o alcance dos objetivos estratégicos, Robson (2005) argumenta que a maneira de criar uma cultura de alto desempenho é construir sistemas de medição de desempenho que encoraja estados psicológicos específicos. Sistemas desenhados usando os princípios psicológicos adequados, poderá levar a uma rápida mudança no comportamento das pessoas e criar uma cultura de alto desempenho. Ele comenta que as pessoas se comportam de maneiras diferentes e tendem a se comportar de acordo com a sua percepção individual da situação. Numa cultura de alto 
desempenho as pessoas deveriam se comprometer para que, além das suas atividades operacionais diárias, parte do seu trabalho seja atuar na melhoria do desempenho da organização. Um sistema organizacional que ajude a criar tal percepção encoraja uma cultura de alto desempenho e, qualquer sistema que crie barreiras para tal percepção estará impedindo o alto desempenho.

Simons (2000) argumenta que o nível de dificuldade para alcançar os objetivos afeta diretamente a motivação para atuar no alcance dos objetivos. Pesquisas sobre o comportamento humano sugerem que a criatividade e iniciativa individual pode ser maximizada quando as pessoas trabalham sob uma pressão adequada e, que retirando a pressão o desempenho e a criatividade reduzem bastante. As metas de desempenho devem ser adequadamente desafiadoras; as metas não podem ser nem "quase impossíveis" e nem "extremamente fáceis".

Conforme Vieira e Cardoso (2003), é importante perceber que a aplicação eficiente de ferramentas de gestão não significa que as organizações serão bem-sucedidas. Perceber os indivíduos com seus valores, crenças, sonhos e expectativas e como agentes ativos da organização, é entender que serão eles os verdadeiros instrumentos de ação, desde que aceitem e compreendam, a partir de seus valores, esses instrumentos como necessários para a criação, ou manutenção, de certa vantagem competitiva para alcançar maiores níveis de eficiência e eficácia. A arquitetura organizacional poderá servir de âncora ou impulso à transformação organizacional, mas mantém a dependência dos valores individuais. KAPLAN e NORTON (1997, p. 283)

O Uso de indicadores como linguagem ajuda a traduzir conceitos complexos e freqüentemente obscuros em idéias mais precisas que alimentam e mobilizam todos os indivíduos em ações dirigidas à realização dos objetivos organizacionais. A ênfase na construção de relações de causa e efeito no BSC gera um raciocínio sistêmico, permitindo que os indivíduos nos diversos setores da organização compreendam como as peças se encaixam, como o seu papel influencia o papel das outras pessoas, alem de facilitar a definição de vetores de desempenho e as iniciativas correlatas que não apenas medem a mudança, como também a alimentam.

A relação de causa e efeito entre os indicadores de desempenho deve, de alguma maneira, estar vinculada aos objetivos financeiros da organização. Quanto mais competitivo e mais rápidas forem as mudanças no ambiente, mais necessário se torna entender como e quais as ações e atividades contribuem para aos resultados. Neste caso é necessário distinguir entre os indicadores que levam, ou mostram as tendências para atingir os resultados e os indicadores que apenas mostram quais foram os resultados.

Os indicadores de resultado (lagging indicators) mostram resultados passados e já ocorridos e, não podem mais serem alterados como por exemplo: lucratividade, ROI, ROCE, participação de mercado, etc. Os vetores de desempenho ou indicadores de tendência (leading indicators) são aqueles que levam, ou ajudam a levar, ao desempenho como por exemplo: produtividade, treinamento, qualidade, flexibilidade, reclamação de clientes, inventário em processo, etc. 
As medidas de resultado sem os vetores de desempenho não indicam como os resultados são alcançados e não indicam de maneira clara se a estratégia está sendo implementada com sucesso ou não. Da mesma forma, os vetores de desempenho, sem as medidas de resultados, podem permitir que a empresa alcance melhorias operacionais no curto prazo, mas não indicam se estas melhorias levam a um melhor desempenho financeiro.

Neste contexto, Kaplan e Norton $(1997,2001)$ propõem o balanced scorecard (BSC) como forma de gestão da estratégia. O BSC reflete o equilíbrio entre objetivos de curto e longo prazo, entre medidas financeiras e não financeiras, entre indicadores de tendência e indicadores de resultados e, entre as perspectivas internas e externas. Todo sistema de gestão e indicadores de desempenho, para ser completo, deve especificar de que maneira as melhorias nas operações, no atendimento aos clientes e em novos produtos e serviços se relacionam com um melhor desempenho financeiro.

\subsection{Balanced scorecard- BSC}

Os indicadores financeiros são de extrema importância para garantir a saúde financeira, a continuidade dos negócios, a satisfação dos acionistas e os recursos financeiros para investimentos e crescimento. Porém, estes mesmos indicadores quando analisados de maneira isolada, são inadequados para analisar o potencial de crescimento, avaliar a trajetória e direcionar o desempenho das empresas no novo contexto global. SIMONS (2000, p. 203)

\footnotetext{
Nos mercados altamente globalizados, competitivos e em constantes mudanças as organizações alcançam o sucesso através dos investimentos e do gerenciamento das suas capacidades e dos ativos intangíveis. As funções especializadas devem ser integradas em processos de negócios baseado no cliente. A inovação em produtos, processos e serviços deve ser criada por funcionários altamente treinados e capacitados, tecnologia de informação de ponta e por processos organizacionais alinhados. Conforme as organizações investem na aquisição destas novas capacidades e ativos intangíveis, o sucesso não pode ser motivado e controlado somente pelos tradicionais indicadores financeiros.
}

Conforme Kaplan e Norton (1997), o BSC é uma ferramenta que traduz a visão e a estratégia da empresa num conjunto de medidas de desempenho e objetivos estratégicos específicos, organizados segundo quatro perspectivas diferentes: financeira, do cliente, dos processos internos e do aprendizado e crescimento. O BSC complementa as medidas financeiras do desempenho passado com medidas dos vetores de desempenho que impulsionam o desempenho futuro, e incorpora objetivos e medidas tanto para o ciclo de inovação de longo prazo como para o ciclo de operações de curto prazo. É uma ferramenta para a implementação da estratégia e não para a sua formulação, embora o "feedback" dos resultados direcione a reformulação das estratégias.

Kaplan e Norton $(1997,2004)$ argumentam que o BSC é um sistema de gestão estratégica, pois deriva de um processo "top-down" norteado pela missão e pela estratégia da empresa. O objetivo principal do BSC é o alinhamento do planejamento estratégico com as ações que levarão 
ao alcance dos objetivos estratégicos. As quatro perspectivas se relacionam umas com as outras numa relação de causa e efeito e podem ser visualizadas através de um mapa estratégico. A execução da estratégia requer que os programas estratégicos sejam gerenciados de maneira ativa e suportados por um mapa estratégico que forneça uma descrição completa de como se cria valor para o negócio em relação às quatro perspectivas:

- A perspectiva financeira descreve os resultados tangíveis da estratégia em termos financeiros e indicam se as estratégias e sua implementação estão contribuindo para o alcance dos objetivos financeiros e assegurando a saúde financeira da empresa.

- A perspectiva do cliente define os direcionadores do crescimento da receita como a satisfação dos clientes, retenção e conquista de novos clientes bem como a proposição de valor para o cliente;

- A perspectiva dos processos internos mostra como as operações, gerenciamento da relação com os clientes, processos de inovação, gerenciamento das leis e regulamentos relativos ao negócio, qualidade e produtividade asseguram a proposição de valor para o cliente e gera impacto nos objetivos financeiros, na satisfação de todos os "stakeholders" e; - A perspectiva do aprendizado e crescimento identifica os ativos intangíveis mais importantes da estratégia e envolve as competências e infra-estruturas necessárias para o desenvolvimento de um clima que propicia a mudança, inovação, excelência operacional e crescimento no médio e longo prazo. FPNQ, 2005, p. 5

O aprendizado deve ser uma intenção estratégica nas organizações e estar internalizado na
cultura organizacional, tornando-se parte do trabalho diário em quaisquer de suas
atividades, em todos os níveis. ...dissemina suas melhores práticas, pratica o
"benchmarking" interno e externo, compartilha informação e conhecimento, desenvolve
soluções e implementa melhorias e inovações de forma sustentada. A organização que
avalia periodicamente seu sistema de gestão e implementa melhorias ou inovações em suas
práticas gerenciais se adapta mais facilmente às mudanças e tem mais condiçôes de atingir
e manter a excelência no desempenho.

Kershaw (2004) reforça que os gerentes devem modificar seus comportamentos e redirecionar o foco de atuação, uma vez que o principal objetivo dos SMD é motivar e reforçar a implantação das estratégias. Fletcher (2004) complementa que o sucesso de longo prazo requer um sistema estruturado de medição e avaliação do desempenho que monitore e reporte a "geração de valor para o negocio" (EVA) como um todo. Para produzir mais EVA temos que entender os indicadores direcionadores de valor. Rodrigues (2005) complementa que existe uma forte relação entre os indicadores mais representativos do BSC e o EVA. 


\section{O estudo de caso}

O estudo de caso foi desenvolvido em uma empresa com faturamento anual em torno de $\mathrm{R} \$$ 55 milhões, localizada no interior do Estado de São Paulo. Trata-se de uma unidade de negócios de uma multinacional americana de grande porte. Seus principais clientes são a GM, Fiat, Honda, Renault, Peugeot e VW. A empresa é certificada ISO / TS 16949 e ISO 14001 e o seu sistema de produção é o de fabricação contra pedido.

Foram levantadas informações sobre o uso do SMD baseado no BSC, alinhamento das estratégias e os indicadores, a coerência dos indicadores em relação às perspectivas do BSC, como este sistema favorece o alcance dos objetivos estratégicos e, também, aspectos do negócio como o produto e mercado, processos e as principais estratégias adotadas. A empresa pratica a metodologia do planejamento estratégico anual, com revisão semestral ou conforme as mudanças no ambiente competitivo. Nestes casos, formula (ou reformula) as estratégias de marketing, financeira, recursos humanos e manufatura, os objetivos estratégicos, bem como o orçamento para prover os recursos materiais e humanos necessários ao alcance dos objetivos estratégicos.

Desde o início da operação no Brasil, no final da década de 90, a empresa adotou as práticas de medição de desempenho com uma configuração participativa que abrange todas as áreas da empresa em todos os níveis. Implantou um sistema de envolvimento e comprometimento dos funcionários, onde sete indicadores principais (em negrito no quadro 1) são monitorados com a participação de todos os funcionários, de todos os níveis. Os resultados alcançados levam a um reconhecimento financeiro na forma de bônus (PLR) pagos semestralmente e que pode atingir até um salário (do funcionário), ou seja, de zero até dois salários adicionais no ano.

O resultado final é um conjunto de objetivos quantitativos e planos de ação com metas, cronogramas e indicadores que abrangem os fatores críticos de sucesso das operações, sustentado por um SMD estruturado conforme as perspectivas do BSC, como pode ser observado no quadro 1 apresentado a seguir.

Os indicadores da perspectiva financeira são os indicadores de resultados, que indicam se as estratégias e sua implementação estão contribuindo para o alcance dos objetivos financeiros. São resultantes da maioria dos indicadores vetores de desempenho das demais perspectivas e, até mesmo de outros indicadores da mesma perspectiva. No quadro 1, alguns indicadores financeiros foram numerados para mostrar a relação de causa e efeito com os demais indicadores e demais perspectivas. Como a empresa utiliza algumas matérias primas especiais, o gerenciamento da utilização de matérias primas " $A$ " foi incluído na perspectiva financeira e não na perspectiva dos processos internos. 
Quadro 1- Objetivos estratégicos e indicadores de medição de desempenho

\begin{tabular}{|c|c|c|c|}
\hline Perspectivas & $\begin{array}{c}\text { Principais Objetivos } \\
\text { Estratégicos }\end{array}$ & Principais Indicadores & $\begin{array}{l}\text { Freqüência } \\
\text { de medição }\end{array}$ \\
\hline \multirow{10}{*}{ Financeira } & \multirow{10}{*}{$\begin{array}{c}\text { EBIT (K US\$) } \\
\text { RONA (\%) } \\
\text { Lucro Bruto (K US\$) } \\
\text { Fluxo de caixa liquido (K US\$) } \\
\text { Numero de giro do inventário } \\
\text { Crescimento da receita, } \\
\text { lucratividade, produtividade e } \\
\text { rentabilidade dos clientes }\end{array}$} & EBIT; RONA; Lucro Bruto (1) & Mensal \\
\hline & & Fluxo de caixa liquido & Mensal \\
\hline & & Capital de giro liquido & Mensal \\
\hline & & Vendas em US\$ e R\$ x orçamento (2) & Mensal \\
\hline & & Numero de giro do inventário (3) & Mensal \\
\hline & & Margem Bruta de contribuição. (4) & Mensal \\
\hline & & Custos variáveis $\mathrm{x}$ orçamento & Mensal \\
\hline & & Custos fixos $\mathrm{x}$ orçamento & Mensal \\
\hline & & \% utilização das matérias primas "A". (5) & Diário \\
\hline & & Acuracidade de inventário em \% & Mensal \\
\hline \multirow{12}{*}{ De Clientes } & \multirow{12}{*}{$\begin{array}{l}\text { Aumento de Market Share } \\
\text { (\% do mercado) } \\
\text { Aumento de novos negócios } \\
\text { (quantidade) } \\
\text { Certificado de Mérito de } \\
\text { Clientes (quantidade) } \\
\text { Fornecer valor para o cliente } \\
\text { com inovação, tecnologia e } \\
\text { satisfação das necessidades } \\
\text { atuais e futuras }\end{array}$} & Índice de entregas no prazo. $(3,4)$ & Semanal \\
\hline & & Prazo de desenvolvimento de produtos (2) & Mensal \\
\hline & & Prazo de entregas de protótipos e amostras & Mensal \\
\hline & & Protótipos aprovados na primeira vez & Mensal \\
\hline & & Número de reclamações de clientes & Diário \\
\hline & & Índice de satisfação de clientes & Semestral \\
\hline & & Auditorias de clientes e órgãos externos & Mensal \\
\hline & & IQF - recebido dos clientes & Mensal \\
\hline & & Índice de devolução de clientes $(\mathbf{1}, \mathbf{4})$ & Diário \\
\hline & & Retorno de produtos em garantia $(\mathbf{1}, \mathbf{4})$ & Semanal \\
\hline & & PPAP aprovados - primeira vez e no prazo. & Mensal \\
\hline & & Atendimento de prazo de entrega de cotação & Mensal \\
\hline \multirow{16}{*}{$\begin{array}{l}\text { Processos de } \\
\text { Negócios } \\
\text { internos e } \\
\text { externos }\end{array}$} & \multirow{9}{*}{$\begin{array}{c}\text { \% de utilização da capacidade. } \\
\text { Índice de Produtividade (1). } \\
\text { 100\% atendimento de entregas. } \\
\text { Zero devolução de clientes. } \\
\text { Zero acidente. } \\
\text { Certificação ISO /TS } 16949, \\
\text { ISO } 14001 \text { e OHSAS } 18001 . \\
\text { Pleno atendimento às } \\
\text { legislações trabalhistas, fiscais } \\
\text { tributarias e do meio ambiente. }\end{array}$} & Volume de produção x orçamento. $(\mathbf{1}, \mathbf{2}, \mathbf{3}, \mathbf{5})$ & Semanal \\
\hline & & \% de utilização da capacidade $(\mathbf{1}, \mathbf{4})$ & Mensal \\
\hline & & Índice de Produtividade $(1,2,3,4,5)$ & Diário \\
\hline & & Índice de Housekeeping e Segurança (5) & Mensal \\
\hline & & Auditoria de Processo & Mensal \\
\hline & & Índice da Qualidade (5) & Mensal \\
\hline & & Auditoria produto & Mensal \\
\hline & & Auditoria do Sistema do Meio Ambiente & Trimestral \\
\hline & & Índice de acidentes - TCIR & Mensal \\
\hline & \multirow{3}{*}{$\begin{array}{c}\text { Informação, Inovação e } \\
\text { Tecnologia }\end{array}$} & Auditoria do Processo de Saúde e Segurança & Semestral \\
\hline & & Auditoria do Sistema da Qualidade & Trimestral \\
\hline & & Custo da Qualidade $(\mathbf{1}, \mathbf{4})$ & Mensal \\
\hline & \multirow{4}{*}{$\begin{array}{c}\text { Qualidade, Produtividade, } \\
\text { Flexibilidade e Custos } \\
\text { Competitivos }\end{array}$} & Índice de Refugos $(1,4,5)$ & Diário \\
\hline & & Índice de Retrabalho. $(1,4,5)$ & Diário \\
\hline & & Pontualidade de entrega dos fornecedor & Mensal \\
\hline & & Índice de qualidade dos fornecedores & Mensal \\
\hline \multirow{5}{*}{$\begin{array}{c}\text { Aprendizado } \\
\text { e } \\
\text { Crescimento }\end{array}$} & \multirow{5}{*}{$\begin{array}{l}\text { Competências estratégicas, } \\
\text { clima para ação, crescimento } \\
\text { das pessoas, habilidade, atitude, } \\
\text { conhecimento, respeito e } \\
\text { trabalho em Equipe }\end{array}$} & Satisfação Interna e Motivação $(\mathbf{1 , 3 , 4 , 5 )}$ & Semestral \\
\hline & & Sugestões por funcionário / ano $(\mathbf{1}, \mathbf{3}, \mathbf{4}, \mathbf{5})$ & Mensal \\
\hline & & Turn Over $(\mathbf{3}, \mathbf{4}, \mathbf{5})$ & Mensal \\
\hline & & Absenteísmo $(3,4)$ & Mensal \\
\hline & & Hrs Treinamento / Funcionário / ano $(\mathbf{1 , 3 , 4 , 5 )}$ & Mensal \\
\hline
\end{tabular}

O grupo de indicadores da perspectiva de cliente demonstra como a empresa fornece valor para o cliente e são "critérios qualificadores" para o fornecimento. Dependendo da necessidade dos clientes alguns indicadores como prazo de desenvolvimento de produtos ou prazo de entrega de protótipos podem se tornar "critérios ganhadores de pedido". A maioria destes indicadores são resultantes da perspectivas dos processos internos e de aprendizagem e crescimento.

Os indicadores dos processos internos mostram como as operações, processos de inovação, 
gerenciamento das leis e regulamentos relativos ao negócio, qualidade e produtividade estão atendendo proposição de valor para o cliente e os objetivos financeiros. O alcance dos objetivos está fortemente correlacionado com as competências estratégicas desenvolvidas pelo aprendizado e crescimento. Já os principais indicadores da perspectiva do aprendizado e crescimento identificam como a empresa está desenvolvendo os seus recursos para suportar as demais perspectivas.

Os resultados obtidos pela gestão estratégica com o BSC, em conjunto com um sistema de administração participativa, demonstram que o BSC proporciona a todos os funcionários ampla compreensão das estratégias da empresa, explicando onde cada um se encaixa no mapa estratégico e como podem contribuir para o alcance dos objetivos estratégicos. Em relação ao comprometimento e participação, os resultados reforçam as teorias de Likert (1979), onde colocar a informação ao alcance de cada grupo de trabalho é uma necessidade para criar no grupo um senso de responsabilidade por custos, desperdícios, desempenho, etc., e para que o grupo reaja inteligente e construtivamente aos problemas gerais da organização.

Embora todos os objetivos estratégicos das perspectivas dos clientes, dos processos internos e de aprendizagem e crescimento tenham sido alcançados nos anos de 2003, 2004 e 2005, os principais objetivos estratégicos da perspectiva financeira (EBIT e RONA) não foram alcançados. O não alcance destes objetivos, conforme levantado durante a pesquisa e nas entrevistas, foram causados pela competição baseada no preço e, principalmente, pela turbulência política e econômica e a grande variação da taxa do Dólar em relação ao Real, ou seja , as variáveis macroeconômicas. Esta conclusão é reforçada por Hitt et al (2005) que argumentam que os retornos superiores são determinados pelas características externas e não apenas pelos recursos e capacidades exclusivos de uma empresa, embora ambos afetem diretamente a rentabilidade.

Pesquisa de Fleury e Fleury (2003) com 470 empresas de pequeno, médio e grande porte nos diversos setores industriais corroboram com os dados deste estudo de caso em relação ao fator preço como determinante competitiva. No mercado automotivo brasileiro atual, mesmo para produtos inovadores e de alta tecnologia, o fator preço é determinante como critério ganhador de pedidos. Todas as demais características como o fornecimento em JIT, KANBAN, PPM conforme as exigências dos clientes, inovação e capacidade de atendimento dos requisitos específicos dos clientes, índice de qualidade de fornecimento (monitorado pelo cliente), diferenciação de produto e processo, auditorias realizadas pelos clientes, certificação ISO / TS 16949, ISO 14001, etc. são apenas critérios qualificadores para o fornecimento. Se para o mesmo produto houver dois ou mais fornecedores, da mesma forma qualificados, a competição passa a ser pelo menor preço.

Mensalmente duas reuniões principais acontecem na empresa para a análise do desempenho. A primeira se refere à reunião mensal da diretoria e gerencia onde todos os resultados dos objetivos e indicadores referentes às quatro perspectivas são discutidos e analisados. A segunda se refere à 
reunião mensal com a participação de todos os funcionários, de todos os níveis hierárquicos de todas as áreas, onde se discute os sete principais indicadores de desempenho, os quais são relacionados com as perspectivas financeira, de clientes e processos internos e externos.

Baseado nos resultados alcançados nas quatro perspectivas e conforme as mudanças do ambiente competitivo ocorrem, o processo de definição e execução estratégica é realimentado, revisado e alterado, se necessário.

\section{Conclusões}

Os objetivos estratégicos da perspectiva financeira são fortemente afetados pelas variáveis macroeconômicas e competição baseada no preço, mesmo que a atuação da empresa seja em inovação e alta tecnologia. Neste tipo de ambiente competitivo o BSC demonstra ser de grande utilidade para o alcance dos objetivos estratégicos das demais perspectivas e, mesmo demonstrando uma clara relação de causa e efeito entre as medidas de desempenho nas quatro perspectivas, não garantiu o alcance dos objetivos estratégicos da perspectiva financeira da empresa em 2005.

Uma vez que todos os demais objetivos como produtividade, qualidade, satisfação dos clientes (inclusive com certificados de mérito em 2003, 2004 e 2005), maior participação de mercado, etc., foram alcançados, sem esta relação de causa e efeito os resultados financeiros poderiam ter sido ainda piores. $\mathrm{O}$ alcance dos objetivos estratégicos das demais perspectivas tem forte influência sobre os principais objetivos financeiros, mas não garante que os mesmos sejam alcançados.

Estabelecer uma cultura voltada para a implementação, execução e controle das estratégias, apoiada por sistemas adequados de medição de desempenho, fortalece o ambiente interno das organizações e as mudanças no ambiente de negócios são mais facilmente detectadas, favorecendo tomadas de ações baseadas em fatos e dados.

Uma vez que o desempenho organizacional é o resultado de todos os esforços, atividades e ações realizadas todos os dias dentro de uma organização, a chave para a melhoria do desempenho não está em enunciar as aspirações da empresa e nem na "pressão" por um desempenho melhor. A solução está em assegurar um ambiente organizacional comprometido com os resultados e que incentive um processo decisório alinhado com os objetivos estratégicos da organização.

\section{Abstract}

The objective of this article is to discuss the main results of a case study in relation to the implementation and execution of strategies with Balanced Scorecard use - BSC. Bases on the search for competitive advantages and management of operations, where the competitive environment force the companies review their strategies and competences. The strategic management and the performance analysis should base on metrics and indicators that show coherence among the 
indicators, the critical factors of success, the competitive strategies and the strategic objectives. Strategies well formulated are not enough if there are not implementation, execution and control, in other words, an administration gone directed to the achievement of the strategic objectives. BSC provides wide understanding of the strategies, explaining where each employee is fit in the strategic map and how they can contribute for the achievement of the objectives. Although it favors the achievement of the strategic objectives of the several perspectives, it doesn't assure, in specific cases, the reach of the main objectives of the financial perspective.

Key-words: strategy execution; performance measuring system; balanced scorecard; competitive advantage.

\section{Referências bibliográficas}

BOURNE, Mike; NEELY, Andy. Implementing Performance Measurement Systems: A literature Review. International Journal of Business Performance Management, v. 5, n 1, 2003, pp. 1-24.

cross ${ }^{\text {ref }}$

BOURNE, Mike; KENNERLY, M.; FRANCO-SANTOS, M. Managing through measures: A study of impact on performance. Journal of manufacturing technology management, v. 16, n. 4, 2005, pp. 373 - 395.

cross ${ }^{\text {ref }}$

CHENHALL, Robert H. Integrative Strategic performance systems, strategic alignment of performance, learning and strategic outcomes: an exploratory study. Accounting, Organizations and Society, v. 30, 2005, pp.395-422

cross ${ }^{\text {ref }}$

FLETCHER, Harold; SMITH, Darlene, B. Managing for value: developing a performance measurement system integrating economic value added and the balanced scorecard in strategic planning. Journal of Business Strategies. v. 21, n.1, 2004, pp. 1-17.

FLEURY, A. C. C.; FLEURY M. T. L. Estratégias competitivas e competências essenciais: perspectivas para a internacionalização da industria no Brasil. Gestão da Produção, v. 10, n. 2, 2003, pp.129-144.

cross ${ }^{\text {ref }}$

FPNQ - Fundação para o premio nacional da qualidade. Planejamento do sistema de medição do desempenho. Relatório do comitê temático, 2002, $2^{\mathrm{a}}$ edição.

FPNQ - Fundação para o prêmio nacional da qualidade. Rumo à Excelência: Critérios para a avaliação do desempenho e diagnostico organizacional, 2005

HAWAWINI, Gabriel, SUBRAMANIAN, Venkat; VERDIN, Paul. Is Performance Driven by Industry-or FirmSpecific Factors. Strategic Management Journal; v.24, 2003, pp. 1-16

cross ${ }^{\text {ref }}$

HILL, Terry. Manufacturing strategy - text and cases. Boston: Richard D. Irwin, 1989.

HITT, Michael A. ; IRELAND, R. D. ; HOSKISSON, R. E. Administração Estratégica : Competitividade e Globalização. São Paulo: Pioneira Thomson Learning, 2005

KAPLAN, R. S. ; NORTON, D. P. A estratégia em ação: balanced scorecard. Rio de Janeiro: Campus, 1997.

Organização orientada para a estratégia: como as empresas que adotam o balanced scorecard prosperam no novo ambiente de negócios. Rio de Janeiro: Campus, 2001.

Mapas estratégicos - Balanced Sccorecard: convertendo ativos intangíveis em resultados tangíveis. Rio de Janeiro: Elsevier, 2004.

KAPLAN, R. S. How the balanced scorecard complements the McKinsey 7-S model. Strategy \& Leadership; v, 33, n. 3, 2005, pp. 41-46. 
KENNERLEY, Mike; NEELY, Andy. A Framework of the factors affecting the evolution of Performance Measurement Systems. International Journal of Operations \& Production Management, v 22, n 11, 2002, pp 1222 1245.

cross ref

KENNERLEY, Mike; NEELY, Andy. Measuring Performance in a Changing Environment, International Journal of Operations \& Production Management, v 23, n 2, 2003, pp 213 - 229.

cross ${ }^{\text {ref }}$

KERSHAW, R. Measuring performance during economic slowdowns. Cost Management, v.18, n.5, sept/oct. 2004, pp. 31-37.

LAWRIE, Gavin; COBBOLD, Ian. Third-generation Balanced Scorecard: Evolution of an Effective Strategic Control Tool. International Journal of Productivity and Performance Management, v. 53 n 7, 2004 pp. 611-623.

cross $^{\text {ref }}$

LIKERT, Rensis. Novos padrões de administração. São Paulo: Pioneira, 1979.

MINTZBERG, Henry ; QUINN, James B. O processo da estratégia, Bookman companhia editora, 2001

NEELY, Andy. Measuring Business Performance. Profile Books, The Economist Newspaper, 1998.

NEELY, Andy; RICHARDS, Huw; MILLS, John; PLATTS, Ken. Getting the measures of your business. Cambridge, UK: Cambridge University Press, 2002.

NIVEN, Paul R. Balanced scorecard diagnostics: maintaining maximum performance. John Wiley \& Sons, New Jersey, 2005

ROBSON, Ian. Implementing a performance measuring system capable of creating a culture of high performance. International Journal of Productivity and Performance Management, v. 54, n.2, 2005, pp. 137-145.

cross

RODRIGUES, Maxweel Veras. Método para determinação da escala de priorização de ações estratégicas fundamentado no grau de inter-relacionamento entre os indicadores das perspectivas do balanced scorecard (BSC) e o valor econômico adicionado (EVA). Tese de Doutorado, Engenharia de Produção, UFSC, Florianópolis, 2005.

SIMONS, Robert; Performance measurement and control systems for implementing strategy: Text and Cases. New Jersey: Prentice-Hall. Inc, 2000

SLACK, Nigel et al. Administração da produção; São Paulo, Editora Atlas, 2 edição -2001

TANGEN, Stefan; Performance measurement: From philosophy to practice. International Journal of Productivity and Performance Management, v. 53, n. 8, 2004, pp 726- 737.

cross ${ }^{\text {ref }}$

VIEIRA, P. Reis ; CARDOSO, A. S. Rito; Construção, desconstrução e reconstrução se sistema de valores nas organizações. Cadernos EBAPE.BR, v 1, n 2 ; Dezembro 2003.

VOELPEL, Sven C. et al, The organizational fitness navigator: Enabling and measuring organizational fitness for rapid change. Journal of Change Management; v. 4, n. 2; 2004.

WAAL, Andre. Stimulating performance-driven behavior to obtain better results. International Journal of Productivity and Performance Management; v. 53, n. 4, 2004, pp $301-316$.

crossef

YIN, Robert K. Estudo de caso: Planejamento e métodos. Porto Alegre: Bookman, 2001. 
Nome: José Tarcísio Greve

Filiação institucional: Engelhard

Endereço: Rua Dr. Camilo Marques Paula, n51

CEP 1333-440- Indaiatuba - SP, Brasil

e-mail: greve.idt@terra.com.br

Nome: José Antonio Arantes Salles

Filiação institucional: Universidade Metodista de Piracicaba

Departamento: Programa de Pós-Graduação em Engenharia de Produção

Função: Professor

Endereço: Rodovia Santa Bárbara - Iracemápolis, Km 1

CEP 13450-000 - Santa Bárbara D'Oeste, SP - Brasil

Telefone: (19) 31241761

e-mail: jasalles@unimep.br

Recebido para publicação em: 10/04/07

Aceito para publicação em: 04/05/07 